\title{
Research on the Utilization and Evaluation of Library Resource Discovery Systems in China
}

\author{
Linlin Song, Sun Yat-sen University, Guangzhou, China \\ Haitao Li, Sun Yat-sen University, Guangzhou, China \\ Shihui Li, Sun Yat-sen University, Guangzhou, China
}

\begin{abstract}
According to the investigation of library resources discovery system construction in 20 universities in China, the aggregation discovery service provided by the multi-source aggregation function, the discovery function is based on aggregation and the comprehensive revealing function. This article evaluates user usage and acceptance based on refinements of the functions mentioned above. The investigation shows that compared with the diversity of function, users are more concerned about the practicability, the intuition and the academy. Thus, systems should choose the best sources and pay attention to the metadata normalization, and enhance the correlation to standard datasets.
\end{abstract}

\section{KEYWORDS}

Aggregation Function, Discovery Function, Resource Discovery System, Users' Evaluation

\section{INTRODUCTION}

The Library Resource Discovery System (RDS), based on information organization and aggregation theory, is a system which provides users with integrated service of information resources through pre-indexing and pre-aggregation procedures such as harvesting, mapping, and transferring the information metadata from heterogeneous platforms and databases.

A resource discovery system is the integration of multiple service modes. Compared with the traditional single full-text service, the resource discovery system not only integrates the traditional service methods of library information retrieval, reader authentication, appointment renewal, etc., but also provides new service functions such as comment labels, full-text acquisition, academic recommendation, citation display, and collection revelation. These functions enable users to retrieve, display, sort, and acquire all the library resources in an interface, thus helping users to realize the integration of multiple service modes and offer various options to access resources, in line with the internet users' demand.

The RDS has innovated the way of resource organization, integrated the information services of libraries, and improved the intellectualization, somatization, correlation and visualization of library information resources. The application of new technology will be embodied by a variety of new functions. The user's utilization and evaluation of the existing library resources discovery system will provide important guidance and reference for the improvement and perfection of the resource discovery system. 


\section{LITERATURE REVIEW}

In the Chinese library and information science field, the research on the resource discovery systems, a new thing in library information management systems, began in 2011. There are more than 80 related research papers, whose topics are mainly as follows:

TOPIC 1: Comparative Studies on existing resource discovery systems.

These studies aim to introduce and propagate the existing system, helping more libraries and users; in addition, to provide reference for libraries to select and construct the resource discovery system.

The respondent systems are Primo, EBSCO Discovery Service (EDS), Find+, Summon, WorldCat Local, Chaoxing Discovery, etc. The contents consist of history, UI designs, resource ranges, the discovery function, the acquisition function and personalized services.

This topic has the largest number of papers comparing with others, Yu (2017), Ge (2017), Zhu (2015), and Sun (2013), who introduced the development status of each system and their localization in every university library. Both the aims mentioned above have been achieved.

Jason Vaughan (2008), who performs an internal and external research into library web-scale discovery services from the librarians who are participants in the discovery conversation in academic library and the library vendors which have developed these services. They made a recommendation for UNLV Libraries to select a suitable library web-scale discovery system.

Richard Guajardo (2017) introduced the University of Houston Libraries' various discovery options. These include an open-source tool, a federated search product, and two index-based discovery systems. He summarizes important criteria for evaluating discovery systems and recounts valuable lessons that may be applied during future system-evaluation processes and implementations.

Aaron F. Nichols (2017) surveyed heads of reference and instruction departments in research and land-grant university libraries. The survey results revealed common practices with discovery tools among academic libraries. This study also draws connections between operational, instructional, and assessment practices and perceptions that participants have of the success of their discovery tool. Participants who indicated successful implementation of their discovery tool hailed from institutions that made significant commitments to the operations, maintenance, and acceptance of their discovery tool. Participants who indicated an unsuccessful implementation, or who were unsure about the success of their implementation, did not make lasting commitments to the technical maintenance, operations, and acceptance of their discovery tool.

TOPIC 2: The thorough analysis of functions of resource discovery systems.

Compared to the overall introduction of the previous topic, literature related to this subject are more concerned with the in-depth analysis and evaluation of a particular function. Kou (2016) evaluated the retrieval function in Chinese language. Peng (2016) and Zhao (2014) studied the aggregation function. Cheng (2015) and Xiong (2011) focused on the metadata, while Tian (2014) focused on the visualization function.

On the basis of function analysis, Dou (2012) believes that in order to fully use the various functions of the system, improve the library service and values in the era of large data, there are two problems that need to be solved. One is to improve the quality of metadata, the other is to enrich the ways of integrating Resource Discovery System with traditional library resource and internet resources.

Stefanie Buck (2011) analyzes the impact of Serial Solutions' Summon ${ }^{\mathrm{TM}}$ on information literacy instruction from librarian perceptions. The survey revealed librarians' ambivalence toward Summon. While some librarians agree that Summon has the potential to change the way librarians teach information literacy skills, it has not been fully integrated into the classroom. 
TOPIC 3: Evaluation of the existing systems combined with users' demands.

There are four papers evaluating the system, and combined with user' demands. They have different emphases. Wang (2015) evaluates from the aspect of system capability, information quality, customer satisfaction and users' preferences. The results show that the degree of interface friendliness, retrieval speed, result relevance and the repetitive rate are the main impact factors. By analyzing a questionnaire, Gao (2016) surmised that users hope more discipline services can be provided by the system, and they are satisfied with functions such as collection displaying, linked electronic resources, relevance ranking, error correction and hints of search terms, faceted browsing and so on.

Zhang (2014) analyzed the unskilled users' experience in different disciplines, and concludes that although students from different majors have different demands in interfaces, implementation, results display and personalized function, they maintain a high degree of consistency in the demands of resource integration, terms hints and faceted browsing of search results. Liu (2012) suggests that in a group of college students, the effective functions are relevance ranking, linked electronic resource, automatic error correction, reviewing, faceted browsing of searching results, custom tags, custom catalogues and collection display.

David Wells (2016), who examines transactional logs from the Ex Libris Primo installation of Curtin University Library sampled between 2013 and 2015, together with the results of a user survey conducted in 2014, to investigate actual patterns of use and perceptions of value in the available discovery system functionality. The evidence collected supports the original contention of discovery system designers that the single-search box approach adopted by Google and other internet search engines is an appropriate form for library catalogue design. On the other hand, discovery system users clearly value functionality corresponding to traditional library tasks over attempts to locate the catalogue in the conceptual framework of social media.

The research content of this paper is closest to topic 3, and the following research is proposed on the basis of existing literatures. First, due to the continuous updating of technology, functions of resource discovery systems have been improved. For example, the wide application of revealing and visualization technology has comprehensively improved the users' experience. However, it has not been thoroughly studied in the existing literature. This paper will comprehensively evaluate users' demand and experience combined with the results of topic 3. Second, most of the functions mentioned above are based on the researchers' personal experience, which are a lack of logical and theoretical support and an inability to cover all functional design in the resource discovery system. With the guidance of resources aggregation, this paper will list every key function in the using process and provide references for libraries to choose suitable services, according to usage path and the logical frame designed for the system. Third, the existing literature merely suggest users' satisfaction degree in various functions, but they haven't pointed out the reason. This paper will deeply analyze the theoretical basis and technical support of each function, extract the key factors of improving functional service and provide practical methods of improving users' satisfaction.

\section{INVESTIGATION ON RDS IN CHINA}

In order to fully understand the construction of library resource discovery system in a domestic university library in China, this paper, referring to the university rankings published in the China University and Discipline Professional Evaluation report (2017-2018), has selected 20 universities' ${ }^{1}$ library resource discovery systems as respondents. It is intended to grasp the current status of existing systems and fully collect the functions of aggregation and discovery as the object and reference for users' utilization and evaluation. 


\section{SCOPE AND METHOD}

The content of this survey involves the following aspects: resource discovery systems' presentation modes; analysis and utilization of retrieval results; and new functions that the traditional library search tools do not have. This survey uses the method of online investigation. We logged into every library's resource discovery system, and compared the search results gained by the same term but in both English and Chinese. We also tried out the aggregation and discovery function of the resource discovery system, and summarized the trial experience. Table 1 displays the RDS in 20 university libraries in China.

\section{ANALYSIS OF INVESTIGATION RESULTS}

\section{High System Configuration Rate and Multiple Construction Methods}

All of the 20 university libraries surveyed have resource discovery systems. The construction of these systems can be summarized into two ways. One way is to build based on the redevelopment of existing commercial systems. At present, the widely used discovery systems are Primo System by ExLibris (4), EBSCO Discovery Service (EDS) by EBSCO (1), Find+ System by EBSCO \& Nanjing University Digital Library (6), and Summon System by Serials Solution (10). The Summon System has a wider range of uses.

Through the secondary development of the existing system, the system can basically realize one-stop type obtains and discovery towards the library collection resources and the electronic resources. Systems are similar in feature setups such as the search fields, types, strategies, limits as well as the result display and strains. The experimental results show that the response time ranking from short to Long is EDS, Find+, Summon, Primo, and the relative precision ranking from high to low is summon, Find+, EDS, Primo, and the relative recall ranking from high to low is Summon, Find+, Primo, EDS, repetition rate ranking from low to high is EDS, Summon, Find+, and Primo.

Another way is to buy and use off-the-shelf resource discovery systems which are common in Chinese retrieval systems. The commonly used systems include the e-reading system by CALIS (2), Chaoxing Discovery System (11) and so on. This is done mainly to solve the incompatibility problem of Chinese resources in the environment where the mainstream resource discovery system is mostly in a foreign language. Compared with foreign language systems, the Chinese system has more academic auxiliary function, especially in visual analysis and display.

\section{Configure a Dual System of Chinese and Foreign Languages}

Many libraries choose to configure Chinese and foreign language dual systems to meet the needs of different users because the localization and compatibility of foreign language resource discovery systems remains to be improved. There are 11 out of 20 libraries surveyed configuring a dual system. All of them choose the Chaoxing discovery system as Chinese system, as for the foreign system, Summon (7), Find+ (3), EDS (1) are used. There are nine libraries that configure a single system, and the systems are Primo (4), Summon (3), and Find+ (2). Through the investigation, it was found that the retrieval data option of single system is closely related to the searches' language. When tapping into Chinese searches, the system will automatically choose Chinese databases. The results can be displayed in a foreign language, however mostly the simple translation of origin version. Therefore, configuring a dual system is vital for enhancing retrieval efficiency.

\section{Integration Sources are Mainly Library Resources}

The investigation shows that the resource discovery system of each university can basically realize one-stop retrieval towards the library's resources. The document type covers catalog data, periodical papers, e-books, dissertations, newspapers, patents, etc., and some libraries can also achieve the aggregation of each version of the document resources. There are two aspects in resource integration that need to be strengthened. One is multimedia resources, which is out of the one-stop retrieval range 
Table 1. The RDS in 20 university libraries in China

\begin{tabular}{|c|c|c|c|c|}
\hline \multirow[t]{2}{*}{ Universities } & \multicolumn{4}{|c|}{ RDS } \\
\hline & $\begin{array}{l}\text { RDS in } \\
\text { Chinese }\end{array}$ & $\begin{array}{c}\text { RDS in } \\
\text { Foreign } \\
\text { Language }\end{array}$ & Union RDS & Website \\
\hline Tsinghua University & & & Primo & $\begin{array}{l}\text { https://tsinghua-primo.hosted.exlibrisgroup. } \\
\text { com/primo-explore/search?vid=86THU }\end{array}$ \\
\hline Peking University & & & Summon & http://www.lib.pku.edu.cn/portal/cn \\
\hline Zhejiang University & & & Summon & http://libweb.zju.edu.cn/libweb/ \\
\hline Fudan University & & & Primo & http://www.library.fudan.edu.cn/\# \\
\hline Nanjing University & Chaoxing & Find + & & http://lib.nju.edu.cn \\
\hline $\begin{array}{l}\text { Renmin University } \\
\text { of China }\end{array}$ & Chaoxing & Find + & & http://www.lib.ruc.edu.cn \\
\hline $\begin{array}{l}\text { Sun Yat-sen } \\
\text { University }\end{array}$ & Chaoxing & EDS & & http://library.sysu.edu.cn \\
\hline $\begin{array}{l}\text { Central South } \\
\text { University }\end{array}$ & Chaoxing & Summon & & http://lib.csu.edu.cn \\
\hline $\begin{array}{l}\text { Southeast } \\
\text { University }\end{array}$ & & & EDS & http://eds.b.ebscohost.com/eds/search/ \\
\hline Nankai University & & & Find + & http://www.lib.nankai.edu.cn \\
\hline Jilin University & $\begin{array}{l}\text { Chaoxing, } \\
\text { E-readign }\end{array}$ & Summon & & http://lib.jlu.edu.cn \\
\hline $\begin{array}{l}\text { Shandong } \\
\text { University }\end{array}$ & Chaoxing & Summon & & http://www.lib.sdu.edu.cn/portal/index.aspx \\
\hline $\begin{array}{l}\text { Xi'an Jiaotong } \\
\text { University }\end{array}$ & $\begin{array}{l}\text { Chaoxing, } \\
\text { E-readign }\end{array}$ & Summon & & http://www.lib.xjtu.edu.cn \\
\hline Wuhan University & & & Find + & http://www.lib.whu.edu.cn/web/default.asp\# \\
\hline $\begin{array}{l}\text { Huazhong } \\
\text { University of } \\
\text { Science and } \\
\text { Technology }\end{array}$ & Chaoxing & Summon & & http://www.lib.hust.edu.cn \\
\hline $\begin{array}{l}\text { University of } \\
\text { Science and } \\
\text { Technology of } \\
\text { China }\end{array}$ & Chaoxing & Find+ & & http://lib.ustc.edu.cn \\
\hline $\begin{array}{l}\text { Harbin Institute of } \\
\text { Technology }\end{array}$ & Chaoxing & Summon & & http://www.lib.hit.edu.cn \\
\hline Sichuan University & & & Primo & http://lib.scu.edu.cn/sculib \\
\hline Tongji University & Chaoxing & Summon & & $\begin{array}{l}\text { http://www.lib.tongji.edu.cn/site/tongji/index. } \\
\text { html }\end{array}$ \\
\hline $\begin{array}{l}\text { Shanghai Jiao Tong } \\
\text { University }\end{array}$ & & & Primo & http://ourex.lib.sjtu.edu.cn \\
\hline
\end{tabular}

in most libraries. The other one is the limited integration scope of network resources; the current integration work concentrates on Baidu Scholar, Douban, etc., while in some areas such as the open access resources, curriculum sites, social media, etc., the integration still requires more effort. 


\section{Attention to Depth Aggregation of Academic Information Resources}

Under the background of information integration, libraries emphasize the depth aggregation of academic information resources. Tsinghua University Library builds an academic information resources portal, and provides users with a one-stop search for purchased databases. Peking University Library establishes the institutional repository, the open research data platform and the scholars' homepage. LSPD in Renmin University of China classifies resources according to subjects, including subject dynamics, resources, major documents, research agencies and scholars' information. The institutional repository of Renmin University of China focus more on the procedure of scientific research and the maintenance and demonstration of research achievements

\section{Differences Exist in the Analysis Function of Search Results}

According to the analysis of the experimental results, the resource discovery system has the functions of displaying, analyzing and recommending search results. The commonly used clustering standards are literature type, subject, author, publication date, source, etc. However, systems perform differently in function design and use. Results in self-built Resource Discovery Systems are mainly displayed in two-dimensional way. The commercial discovery systems, especially the Chaoxing Discovery System, provide a variety of visual presentations and analysis functions which is significant for enhancing the user experience. It can be proved in the following evaluation of the post.

\section{AGRREGATION DISCOVERY FUNCTION BY RDS}

By analyzing and summarizing the investigation results, this paper summarizes the aggregation discovery function provided by the University Library resource discovery system into the following three types.

\section{Aggregation Function of Multi-Type Information Resources}

The function integrates the same resource of different carriers and relative resources with common content features through the organization and integration of any free media type and format. It is the unified format conversion and normalization preprocessing of metadata records that make the function accessible. For instance, different versions of Harry Potter's novels (books and movies), different content expressions (English and Chinese versions), and the bibliographic records of each novels, are the realization of the FRBR data model.

\section{Resource Discovery Function Basing on Aggregation}

The discovery systems not only provide one-stop retrieval on the basis of various collection resources and aggregated results from multiple databases, but also provide other information resources besides document resources, such as users' data and external resources. Thus, the invisible retrieval demand can be achieved and external resources can be adopted. The system can provide functions like error correction, search tips, and external resources by integrating the searches. Users can add personal tags and comments to share information through correlation functions. With the help of technology like Mashup, online information from websites can be added into the system so that users can not only discover resources but also access book reviews, covers and catalogs while doing one-stop searching.

\section{All-Around Information Resource Revealing Function}

A one-stop searches can retrieve massive search results. However, it can satisfy the different levels, and different basic information needs of users on the condition that the results had been analyzed and revealed effectively.

As for users with ambiguous retrieval needs, the system can provide a browsing service, and set up multiple searches (disciplines, source types, etc.) to help users clarify the need. As for users 
with specific retrieval needs, the system can provide pre-setting function to choose languages and carriers, or reprocessing function of retrieval results, such as sorting, spelling assistants, source recommendation, etc.

The system can visualize the display function for users to analyze results more effectively and to know the current research situation thoroughly. For example, the dispatch volume trend chart of a topic, the academic development trend of a certain area, research development vein of some scholars and the citation and trends of target resources.

\section{USERS' EVALUATION ON RDS}

\section{Designation of Questionnaire}

The content of this questionnaire is as follows, and the detailed contents of the questionnaire are shown in the Appendix.

\section{Purpose of the Questionnaire}

In order to clarify the users' evaluation and requirements of the aggregation discovery function in the existing RDS in Chinese academic libraries, and provide some references for the construction and development of RDS. On the basis of mastering the aggregation and discovery functions of RDS in some well-known academic libraries, this paper selected some undergraduates and postgraduates from Sun Yat-sen University to try and evaluate these functions one by one, so as to obtain more objective evaluation information.

\section{Title of the Questionnaire}

The questionnaire's title is the Evaluation of Library Resource Discovery System's aggregation and discovery functions.

\section{Thinking Road of the Questionnaire}

The specific questions are divided into six parts, which refer to "platforms selection- writing searches and guidance-results display options-searching- results analysis -results recommendation," in accordance with users' retrieval process.

\section{Scheme of the Questionnaire}

The questionnaire consists of System Aggregation Function, System Discovery Function and System Revelation Function.

\section{Questions of the Questionnaire}

There are 48 questions in total in 4 classes. The first is satisfaction assessment, which has 25 questions, and they are designed in a 5-point Likert Scale for the users' experience. The second is importance judgments, 10 sorting questions are designed for users to decide the importance of function and content. The third is preference selection with 11 multiple choice questions set for judgment of preferences of similar functions. The forth class is complements, two of them are open-ended questions for user to add other non-mentioned functions. Each question has a corresponding graphic illustration in order to help respondents understand the questions.

\section{Distributed Audience of the Questionnaire}

The questionnaires were distributed to 150 undergraduates and postgraduates from different discipline backgrounds and different grades in Sun Yat-sen University. The group members take part in the whole process and offer consulting services. 


\section{Collection of the Questionnaire}

150 questionnaires were distributed and all of them were collected. The recovery and the effective rate are both $100 \%$.

\section{Statistical Analysis Method of the Questionnaire}

To analyze the questionnaires, we counted the amount and percentage of each option. Our group calculated the mean and standard deviation of 25 scale questions and counted the frequency of other non-scale questions. As for open-ended questions, word frequency analysis is used. On the basis of analysis, the article uses qualitative analysis to understand the evaluation of the functions and services of the resource discovery system.

\section{RESULTS ANALYSIS OF THE QUESTIONNAIRE}

\section{The Aggregation Function}

The aggregation function of the library resource discovery system relies on the following two parts: first, extensive data sources; second, interoperability processing technology of metadata. Both of them are displayed by the search result.

\section{Aggregation sources}

At present, integrated data sources of libraries include the resource from library collection, library consortia, cooperative projects and network. Users' acceptance of multiple resources performs differently except for collection resources. Table 2 displays the acceptance of aggregation sources.

Table 2. Acceptance of aggregation sources

\begin{tabular}{|c|l|l|l|l|l|l|l|l|}
\hline \multirow{2}{*}{ Score } & \multicolumn{9}{|c|}{\begin{tabular}{c} 
Function \\
\cline { 2 - 8 }
\end{tabular}} & $\begin{array}{c}\text { E-Commerce } \\
\text { Website }\end{array}$ & $\begin{array}{c}\text { Book } \\
\text { Reviews }\end{array}$ & $\begin{array}{c}\text { Open } \\
\text { Courseware }\end{array}$ & $\begin{array}{c}\text { Academic } \\
\text { Search Engine }\end{array}$ & $\begin{array}{c}\text { Social } \\
\text { Media }\end{array}$ & $\begin{array}{c}\text { Academic } \\
\text { Resources of } \\
\text { Non-Collection in } \\
\text { School }\end{array}$ & $\begin{array}{c}\text { Cooperation } \\
\text { Projects } \\
\text { Resources }\end{array}$ & $\begin{array}{c}\text { Library } \\
\text { Consortia } \\
\text { Resources }\end{array}$ \\
\hline $\begin{array}{l}\text { Mean/ } \\
\text { Standard } \\
\text { deviation }\end{array}$ & $2.24 / 0.81$ & $2.36 / 0.91$ & $2.16 / 0.85$ & $1.92 / 0.86$ & $3.16 / 0 / 92$ & $1.73 / 0.68$ & $1.73 / 0.65$ & $1.77 / 0.65$ \\
\hline
\end{tabular}

According to the scale analysis, the most acceptable sources are resources of library consortia, resources of cooperation projects with libraries (for example, Zhejiang University gains e-book from Haithtrust Book Digitization Project), academic resources of other institutions within the school (for example, self-built institutional repositories of departments) and academic search engines.

Acceptable resources that are displayed for assisting the collection of bibliographic records are: book reviews coming from Douban, as well as cover or context of E-commerce websites like Jindong. Open courseware is also accepted by users to a great extent. Unacceptable aggregation sources mainly consists of information from social media like WeChat or Microblog. Users feel disturbed when the hot topics of Microblog were integrated into the library collection search.

In general, the reliability of sources and users' retrieval habits are the main references for choosing aggregated sources. Many users prefer to search in the way they trust, or the method they use most frequently. 


\section{Aggregation granularity}

The investigation suggests that the resource discovery system can integrate books of different editions and with different contents. Take the Story of the Stone as an example. Among numerous resources, the popularity goes down in turn of "the original book $>$ relative journal articles $>$ adapted version of the original book>relative courses on MOOC $>$ various television and movie versions $>$ personal information of Xueqin Cao or Xiaoxu Chen $>$ illustrations or stills $>$ drama theme songs and episodes." Thus, the main object of resource aggregation is still the information of traditional document types.

The users' need of content elements of retrieval results are arranged in the order of "Title," "Document Type," "Author," "Subject," "Subject Term," "Source," "Abstract," "Collection Information," "Book Review/Probation Page," "ISBN," "Edition," "Carrier," "Series." As for the technology of acquiring catalog pages by relative settings, users' acceptance level is "less welcomed." As the results are displayed, 50.09\% of the users prefer all the content elements can be showed. It shows that users still focus more on traditional information descriptions such as titles, subject terms, etc. Thus, these elements are vital for filtering the retrieval results. In addition, users have occasional demand for book reviews, covers and catalogs gained through correlation technology. More effort should be put towards content description in order to satisfy users' demand.

\section{The Discovery Function}

\section{The intelligent resource recommendation function.}

The discovery function refers to the retrieval and access of information, which relies on clear information demand and standard descriptions. To clarify the users' demand, the system can provide recommendation service by aggregating users searches, searching history and cooperation. The specific functions are search reminders, automatic error correction, relative information recommendations and interaction etc. Search reminder are performed in two ways: first, to prompt according to terms frequency; second, to inset thesaurus and prompt standard terms. Among the two methods, users prefer the latter (44.44\%), other $21.84 \%$ users stay neutral. Table 3 displays the acceptance of recommendation and interaction function.

Users do not like the system to record their retrieval preferences or to recommend resources, but they accept automatic error correction functions. They do not accept sharing activities in discovery systems. Only $16.29 \%$ of users add tags frequently on their own; $36.30 \%$ of users never add tags. Many users prefer to communicate with relative specialists (43.25\%) and schoolmates $(37.70 \%)$.

In a word, users hope to protect their privacy while using the system, and they perform inactively in resource sharing. In the follow-up interview, users suggest that the utilization of resource recommended by systems is low and they prefer the face-to-face interaction, considering the trust issues.

\section{The intelligent resource discovery function.}

This function concentrates more on the interlinkage and utilization of external network resources. For example, the Primo System correlates relevant network resources by SFX, so that the book reviews, covers and catalogs are accessible. More extensive correlation refers to adding various databases into the discovery system. For example, to provide characters' introductions when correlated with Wikipedia, or to translate searches automatically when correlated with translators. The system can also provide favorite pages to conserve resources for later use. Table 4 shows the acceptance of the discovery function.

The discovery function is somewhat acceptable for users, because it is rapid and instantaneous. This function helps users to clarify their demand while searching. In addition to the simple introduction, 
Table 3. Acceptance of recommendation and interaction function

\begin{tabular}{|c|l|l|l|l|}
\hline \multirow{2}{*}{ Score } & \multicolumn{3}{|c|}{ Function } \\
\cline { 2 - 5 } & \multicolumn{1}{|c|}{$\begin{array}{c}\text { Resource } \\
\text { Recommendation }\end{array}$} & $\begin{array}{c}\text { Automatic Error } \\
\text { Correction }\end{array}$ & \multicolumn{1}{|c|}{ Book Review } & Tags \\
\hline $\begin{array}{l}\text { Mean/Standard } \\
\text { deviation }\end{array}$ & $2.44 / 0.9$ & $1.96 / 0.76$ & $2.39 / 0.75$ & $3.75 / 1.17$ \\
\hline
\end{tabular}

Table 4. Acceptance of discovery function

\begin{tabular}{|c|l|l|l|}
\hline \multirow{2}{*}{ Score } & \multicolumn{3}{|c|}{ Function } \\
\cline { 2 - 4 } & \multicolumn{1}{|c|}{ Searches Introduction } & Translators & \multicolumn{1}{c|}{ Favorites } \\
\hline Mean/Standard deviation & $2.01 / 0.88$ & $1.84 / 0.85$ & $2.16 / 0.92$ \\
\hline
\end{tabular}

when the search term involves experts and scholars, users want more information, which ranked as research fields"> "published results"> "institutions"> "research projects", "relative scholars"> "cooperation objects" according to importance to order. The information can be gained only by correlative characters' information databases. The popular utilizing ways are in the order of "online reading"> "download reading"> "mobile reading"> "borrow reading."

Library users are open to the linked and usage of network resources. On one hand, users hope to extend the selection range, and on the other hand, they would like to keep traditional utilization patterns. It puts forward higher requirements for updating and the maintenance of the resource discovery system.

\section{Resource Revealing Function}

Information literacy varies from user to user so multilevel and multi-dimensional resource revealing functions combined with the users' usage patterns is necessary.

1. Faceted browsing function.

The faceted browsing function relies on the resource classification in libraries. Users can choose different browsing ways by standards of document type, subject attribute and database source etc. As for the three common searches mentioned above, a user's preference order is database source (32.75\%), subject attribute (27.58\%), document type (24.13\%), and $15.51 \%$ of the respondents have no priority.

This function helps users to find out clear retrieval requirements. Usage habits influence the option which suggests that in the integration process, the foundation of enhancing users' experience is the seamless integration between databases, and the key to its effectiveness is the integration of specific subjects under classified management according to the literature type.

2. Preset auxiliary function.

Users are most accepting of the preset auxiliary function (the mean value is 1.99/0.77). The acceptance level varies from specific functions: $76.34 \%$ of the users want the results to be classified by the preset of document types; $73.01 \%$ of the users expect both Chinese system and foreign language systems, so that they can search information in different languages individually. Users do not like 
to gain a mixed display of results in different languages (the mean value is 2.56/0.93), for instance, inserting Chinese searches while receiving information in foreign languages.

The situation mentioned above is in line with previous research results. More than half the libraries surveyed have installed Chinese and foreign language dual systems. Besides, users can find some related literature translated into a foreign language by using Chinese searches. It provides reference for libraries whether to choose a dual system or not.

3. Post auxiliary function.

Further filtering and location functions is helpful after results display, such as results ranking, spelling suggestions, retrieval suggestions, relative resources recommendation, etc.

As for the standard of results ranking, users' priority order is "relevancy $>$ academic $>$ citation frequency $>$ publication date $>$ collection priority $>$ clicks $>$ other else." Table 5 displays the acceptance of push function.

\section{Table 5. Acceptance of push function}

\begin{tabular}{|c|c|c|l|}
\hline \multirow{2}{*}{ Score } & \multicolumn{3}{|c|}{ Function } \\
\cline { 2 - 4 } & \multicolumn{1}{|c|}{ Research Hotspots } & Highly Cited Papers & Conferences and Lectures \\
\hline Mean/ standard deviation; & $2.18 / 0.84$ & $2.15 / 0.893$ & $2.12 / 0.76$ \\
\hline
\end{tabular}

The overall demand of the push function is partially acceptable. The demand for specific resources such as traditional research hotspots, highly cited articles, and conference lectures is basically the same. Other types of resources required are categorized as "specific professional resources," "e-book/ movies," "PDF, PPT and audio resources," "academic BBS," "relevant blogger or posters," and "bookstores." As for the way of pushing, users' preferences are ranked by "E-mail $>$ My Library $>$ social apps (WeChat, QQ) > messages > RSS."

As one of the common functions of database, the resource push function has been widely recognized by users. Compared with the traditional push of periodical papers based on related topics, the users hope that the contents can be richer and more diverse in form. Audio, videos and materials from social networks are also welcomed, and combined with academic resources. Traditional RSS Feeds are not welcomed by users, because of low accuracy which makes it harder for the usage.

4. Visualization display function.

The visual display function can help users understand the present situation and the trend of this topic clearly. At the same time, users can also intuitively understand node characteristic like related knowledge points, authors, organizations, and so on.

Firstly, the popular fields of visualization display are "subject distribution (18.75\%)"> "document type (17.82\%)"> "publication date (17.36\%)"> "core journals' distribution (14.58\%)"> "author distribution (11.81\%)"> "publisher (11.11\%)"> "region distribution (8.33\%)."

Secondly, users take an acceptable attitude towards Cite space function which shows the core elements, history, and frontier knowledge of a topic (the mean value is 2.16/0.75). The traditional citation and citation trend mapping function is even more welcomed (the mean value is 2.02/0.69). Thirdly, in the options of linked codes, users think the knowledge code is the most effective (50.88\%), then, the citation analysis (35.09\%), and last, the author codes (14.04\%). 
Users generally prefer Chinese discovery systems like the Chaoxing System to foreign resources discovery systems, and the main reason is that Chaoxing System provides various visualization display functions, making the analysis more intuitive. Whatever the displayed patterns, users are most concerned about the depth of the content mining, and they would like the knowledge code to be the first choice which can be realized by semantic retrieval based on fine-grained description. The investigation also shows that the advanced visualization technology is average in performance, and the reasons are as follows. First, a lack of acknowledgement and trusts, and second, Cite space techniques need to import formatted data to gain accurate results while the limited generalization search adaptation cannot support Cite space.

\section{CONCLUSION}

The Library Resource Discovery System is characterized by the ability to aggregate resources from various sources and to provide a one-stop retrieval. The system realizes that integrating data records of multiple versions and multiple carriers and provides seamless research and use. Technologies of discovery, recommendation, and revealing are also adopted, which can clarify the information needs and display resources in multiple levels and multiple dimensions.

However, it is not the amount of resources and functions that really matters. The investigation suggests that users distrust some sources which may cause obstacles while they are browsing. In addition, some functions have a poor performance in acceptance and utilization, which increases the cost of the maintenances for the system. Thus, according to the preliminary investigation and questionnaire evaluation, the suggestions of installing functions are as follows.

\section{Standard Metadata}

The investigation shows that users rely highly on digital resources. They think the e-book is more important than the library paper collections, which requires the system to do more on the basis of collection resources. However, it does not mean that users accept all the digital resources, they just trust resources from academic organizations or authorities, and the book reviews, index, probation pages obtained through mashups and other technologies are just icing on the cake. The demand for multimedia resources is in general. Social network information is seen as an interference or obstacle. Thus, it is necessary to focus on the selection of sources.

The discovery system is based on metadata pre-index and metadata warehousing mechanism, so the aggregation effect is directly related to metadata qualities. According to the feedback, not all the elements are required, and users consider titles, authors, and sources as core elements. However, it doesn't mean that other sources are unimportant, but it tells us that more attention shall be paid to these core elements in metadata correction and automatic extraction. The best way is to process the data sources with manual intervention, and to establish the interoperation model so that information resources can be uniformly aggregated and described based on some standard forms in order to obtaining a better aggregation effect.

\section{Link With Authority Datasets}

At present, there are various discovery functions, including recommendation on the basis of usage $\log$, recommendation on the basis of shared communication and functions on the basis of external chain technologies like Mashup. The acceptances are different towards different functions. Generally, users are cautious about personal privacy, and they hardly use recommendation functions which have no pertinence. The online interaction is expected to be limited to professionals, which greatly restricts the use of communication functions. As for the external chain technology, only resources from authoritative sources will be adopted.

Therefore, the main point of the resource discovery system is the authority and reliability of sources. The authority dataset is the ideal option to achieve the goal. Priorities should be given 
to correlations with classification, thesaurus and thesaurus in SKOS to increase the accuracy of resource organization and to eliminate lexical ambiguity. Then it should be associated with external bibliographic data for enriching the resources. Lastly, the function should be correlated with authoritative documents such as name specification documents and geographic datasets and collect more external resources with authoritative documents such as associated nodes.

\section{Focusing on Academy, Practicability and Intuitiveness of the Revealing Function}

Multi-dimensional and multi-level resource revealing functions can ensure that users with different information literacy competencies can find, identify, select and access resources conveniently and quickly in a way that is most suitable for their behavior habits.

In settings of the revealing function, users need a depth aggregation with limited scope. For example, users do not quite accept the mixed search of Chinese and foreign resources but focus on the academy of the function, hoping to gain depth aggregation based on knowledge nodes. The requirement of intuitiveness makes the visualization features the key factors. The requirement of practicability manifests in that the usage habit will influence the options. The less difficulty in using the functionality, the better. Therefore, the emergence of new visualization technology is not very popular with users.

In short, to meet the demand of users in resource-revealing functions, the primary problem is to reveal the relations between entities which can be achieved by data models with the help of the library resources ontology or existing data models like RDA and BIBFRAME. According to the data model construction, the knowledge content of information resources can be decomposed, and the granularity of information resources can be analyzed. Besides, the content can be extracted, structured and deeply ordered, so that it realizes the depth aggregation and revelation. 


\section{REFERENCES}

Buck, S., \& Mellinger, M. (2011). The impact of Serials Solutions' Summon on information literacy instruction: Librarian perceptions. Internet Reference Services Quarterly, 16(4), 159-181. doi:10.1080/10875301.2011.6 21864

Cheng, Y. (2015). Thoughts and Questions of Metadata of Resources Discovery Systems. Library and Information Service. 59(9), 104-110, 126.

Dou, T., \& Jiang, A. (2012). Analysis and Application Prospects of Resources Discovery System Functions. Library and Information Service, 56(7), 38-43.

Gao, H., \& Zhang, S. (2016). Study on the Current Application of College Library Resources Discovery Systems on the Basis of Demands: An Example of Colleges in Jiangsu Province. Tushuguanxue Yanjiu, 20, 52-57.

Ge, M. (2017). Analysis and Implications of International and Domestic Resources Discovery Systems' Functions. New Century Library, 1, 60-65, 69.

Guajardo, R., Brett, K., \& Young, F. (2017). The evolution of discovery systems in academic libraries: A case study at the University of Houston libraries. Journal of Electronic Resources Librarianship, 29(1), 16-23. doi :10.1080/1941126X.2017.1270097

Kou, J., \& Jia, J. (2016). Comparison Analysis of Chinese Retrieval Functions' Performance in College Library Resources Discovery Systems. Journal of the National Library of China, 25(3), 80-85.

Li, Y. (2017). Application of Resources Discovery System in Library Knowledge Service: Thoughts Basing on the Chaoxing Discovery System. The Library Journal of Henan, 37(6), 110-112.

Liu, X., Cheng, D., \& Guo, C. (2012). Users’ Expectations towards Library Resources Discovery Systems' Functions: Basing on the Research of High School Users in Campus City of Guangzhou Province. Library and Information Service, 56(7), 27-31.

Nichols, A. F., Crist, E., Sherriff, G., \& Allison, M. (2017). What Does it Take to Make Discovery a Success?: A Survey of Discovery Tool Adoption, Instruction, and Evaluation Among Academic Libraries. Journal of Web Librarianship, 11(2), 85-104. doi:10.1080/19322909.2017.1284632

Peng, J., \& Zheng, Q. (2016). Study on Aggregation and Organization of Information Resources. Taking the Discovery System as an Example, 35(3), 80-85.

Sun, Y., Zhang, L., \& Liu, W. (2013). Study on Selections of Resources Discovery System in Libraries. Library Journal, 32(12), 63-70.

Tian, N. (2014). Study On the Visualization Service of Resources Discovery Systems from the Angle of Readers Services. Tushuguanxue Yanjiu, 17, 71-75.

Vaughn, J. (2012). Investigations into library web-scale discovery services. Information Technology and Libraries, 31(1), 32-82. doi:10.6017/ital.v31i1.1916

Wang, H., \& Lu, W. (2015). Study on User Experience Testing of Academic Resources Discovery Systems. New Century Library, 11, 48-51.

Wells, D. (2016). Library Discovery Systems and their Users: A Case Study from Curtin University Library. Australian Academic and Research Libraries, 47(2), 92-105. doi:10.1080/00048623.2016.1187249

Xiong, Y., \& Ou, P. (2011). Construction of Librarian Relative Literature Resources Discovery and Acquisition Systems: On The Basis of Pre-index of Metadata Reposition. Document. Information\& Knowledge, 6, $102-106$.

Zhang, D. (2014). Analysis of Unskilled Users' Experience in the Two Kinds of Resources Discovery Systems: Basing on the Focus Group's Research. Library Work and Study, 1, 104-108.

Zhao, L., \& Wang, J. (2014). Study on Integration of Resources Discovery Systems and OPAC. Library Work and Study, 10, 125-128.

Zhu, Q. (2015). Evaluation Practice and Analysis on Resources Discovery Systems in American College Schools: Examples from Two American Colleges. Journal of the National Library of China, 24(01), 94-99. 


\section{ENDNOTES}

1 These 20 universities in China are Tsinghua University, Peking University, Zhejiang University, Fudan University, Nanjing University, Renmin University of China, Sun Yat-sen University, Central South University, Southeast University, Nankai University, Jilin University, Shandong University, Xi' an Jiaotong University, Wuhan University, Huazhong University of Science and Technology, University of Science and Technology of China, Harbin Institute of Technology, Sichuan University, Tongji University, Shanghai Jiao Tong University 


\section{APPENDIX}

Dear client:

We are the research group of "Cataloguing Reform and Innovation Based on Bibliographic Framework" supported by The National Social Science Fund of China. We are now carrying out the research on the integrated function analysis and evaluation of "library resource discovery system."

"Library resource discovery system" is a "one-stop" resource retrieval and acquisition platform provided by the library. The system covers information from a wide range of sources, and provides various retrieval modes and results analysis functions. It is a platform for the integration and utilization of library resources.

Please fill in this questionnaire according to your experience. Your valuable Suggestions are very important to further optimize the functions of the library resource discovery system. Thank you very much for your help!

Best regards

1. To what extent would you like the library resource discovery system to retrieve books from Jingdong, Dangdang, Amazon and other resources?
A. A huge extent
B. Quite a huge extent
C. An average extent
D. Quite a limited extent
E. A limited extent

2. To what extent would you like the library resource discovery system to retrieve book reviews from websites like Douban, Duxieren, Shiguangwang and so on?
A. A huge extent
B. Quite a huge extent
C. An average extent
D. Quite a limited extent
E. A limited extent

3. To what extent would you like to receive search results with contents of MOOCs, open courses and other online courses? (Figure 1)
A. A huge extent
B. Quite a huge extent
C. An average extent
D. Quite a limited extent
E. A limited extent

4. To what extent would you like to search Baidu Academic, Google academic, Wikipedia and other online academic open resources through the library resource discovery system? (Figure 2)
A. A huge extent
B. Quite a huge extent
C. An average extent
D. Quite a limited extent
E. A limited extent 
Figure 1.

\section{已干课 分类: 历史 $\mid$ 文学 | 艺术 $\mid$ 哲学 $\mid$ 理工 | 文化}

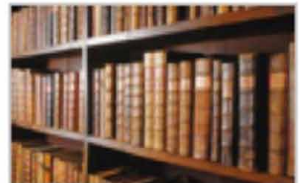

经典阅读的当代思

王福和 浙江工业太

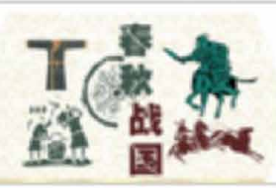

春秋战国大变革的

李山 北京师范大

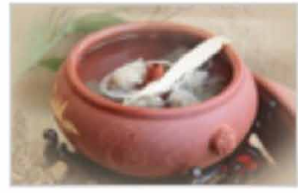

差生大讲堂

张冰隅 华东师范大

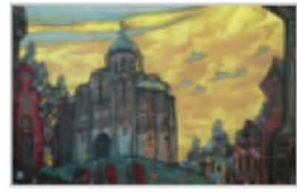

俄罗斯文学 (下)

刘亚丁 四川大学

Figure 2.

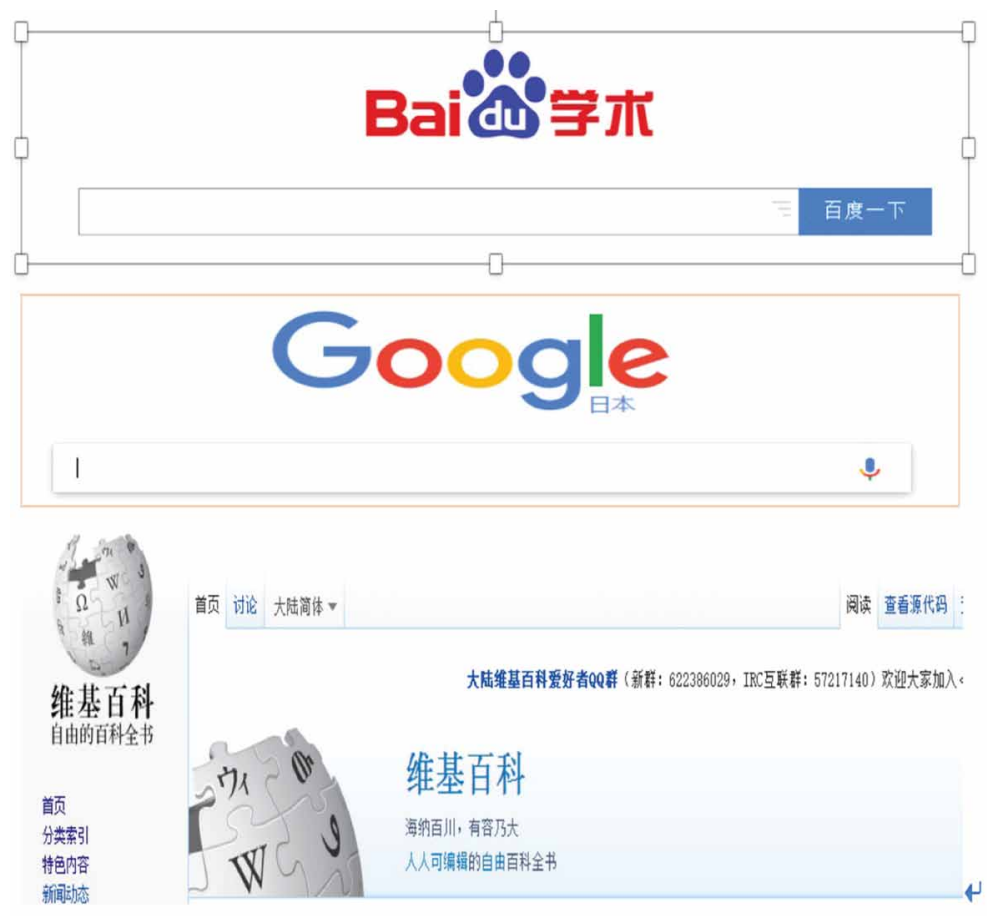

5. To what extent would you like to retrieve literature-related social information through the library resource discovery system? (For example, from BBS, weibo, WeChat, etc.) (Figure 3)
A. A huge extent
B. Quite a huge extent
C. An average extent
D. Quite a limited extent
E. A limited extent

6. To what extent would you like to find other school resources, such as relevant information of school institutions or research results of teachers and students, through the school library system? (Figure 4) 
Figure 3.
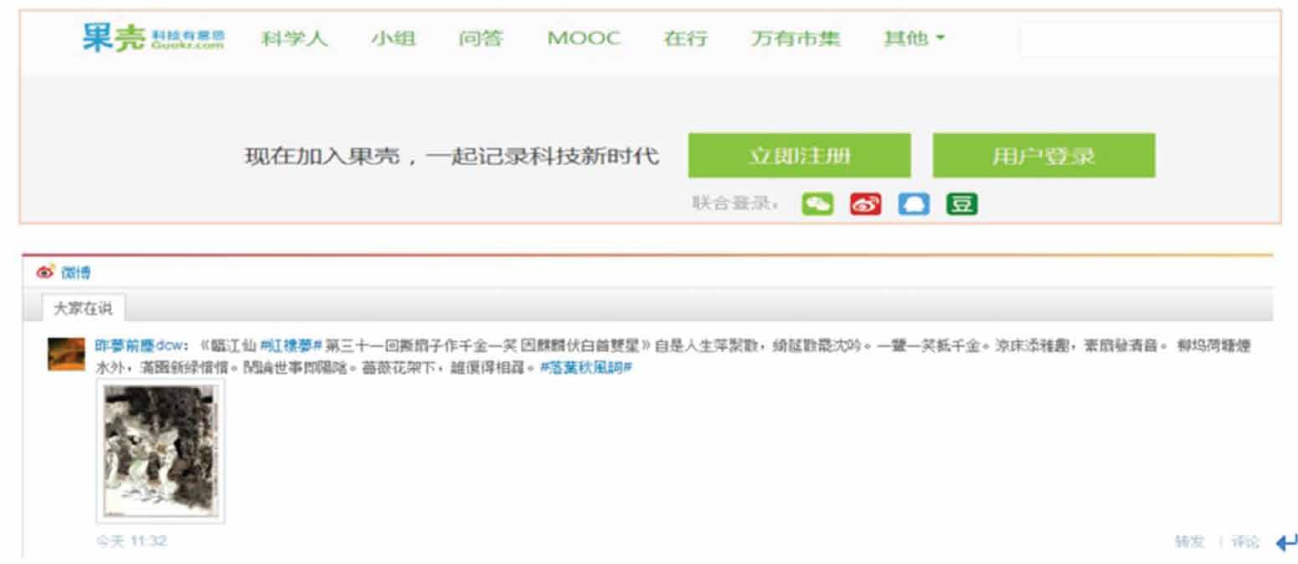

Figure 4.

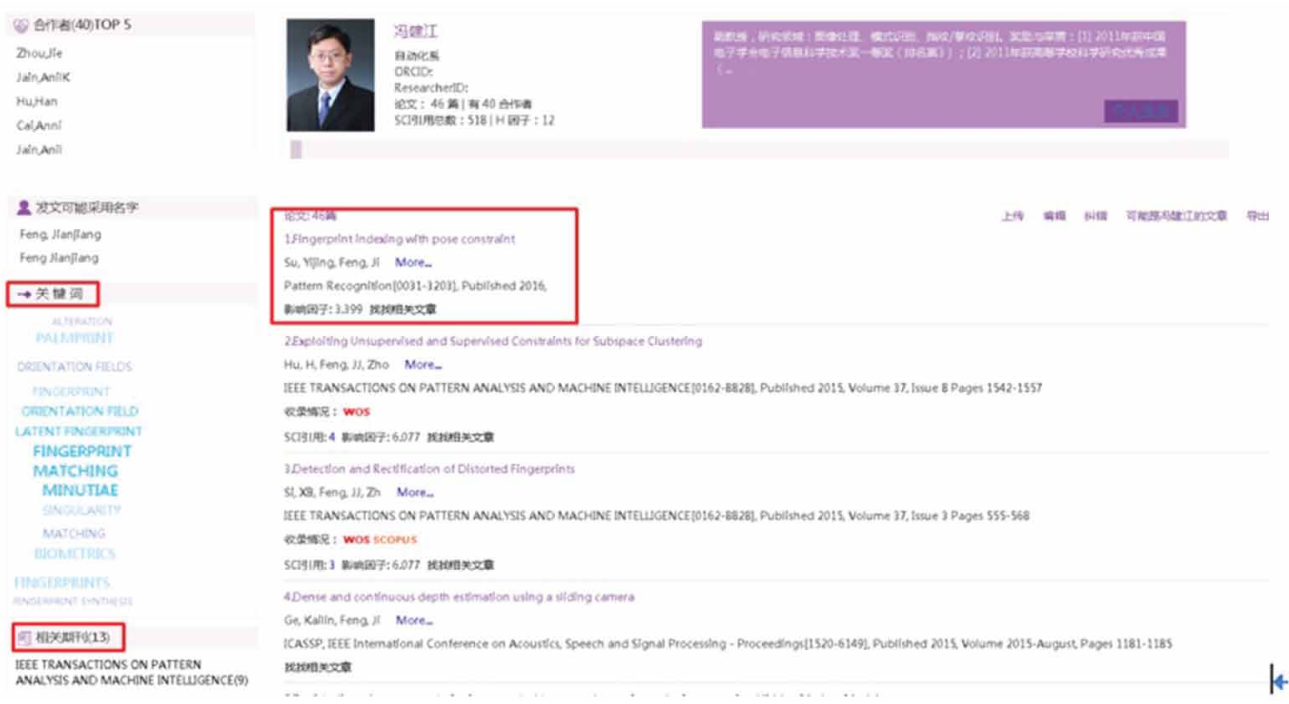
A. A huge extent
B. Quite a huge extent
C. An average extent
D. Quite a limited extent
E. A limited extent

7. To what extent would you like the resources of domestic and foreign cooperation projects can be retrieved through the library system of our university? (for example, the U.S. HathiTrust e-book)

(Figure 5)
A. A huge extent
B. Quite a huge extent
C. An average extent
D. Quite a limited extent
E. A limited extent 
Figure 5.

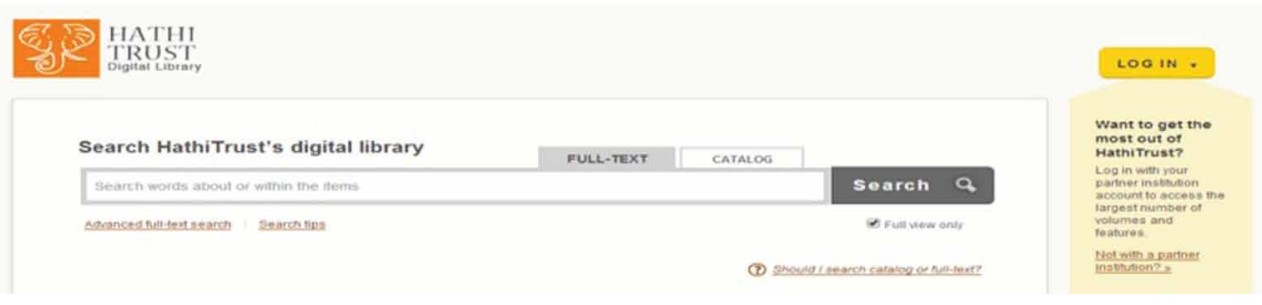

8. Do you prefer obtaining the Chinese and English resources through the same search box (as shown in Figure 6) or through the separate search box (as shown in Figure 7)?
A. The same search box
B. The separate search box

Figure 6.

说明：在本校可用的主要中英文资源中进行内容整合检索

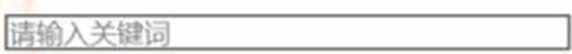

Figure 7.

\section{智慧搜索馆藏查询期刊导航我的图书馆}

\section{中文检索 外文检索}

一站式搜索本校已购的主要中英文资源以及网络开放获取资源

9. To what extent would you like to receive foreign language literature by input Chinese search terms?
A. A huge extent
B. Quite a huge extent
C. An average extent
D. Quite a limited extent
E. A limited extent

10. Which of the following would you like to choose during your retrieval process? (optional)
A. Multiple databases (Figure 8)
B. Multiple disciplines (Figure 9)
C. Multiple literature types (Figure 10)
D. Not to matter 
Figure 8.

\section{标记全部}

\section{田 The Arts 艺术研究文献数据库}

\section{由 ABI 经济管理商业期刊数据库}

$\boxplus \mathrm{CSA}$ 原剑桥科学文摘一人文与社科数据库

\section{曰PQDT 全球博硕论文数据库}

Figure 9.

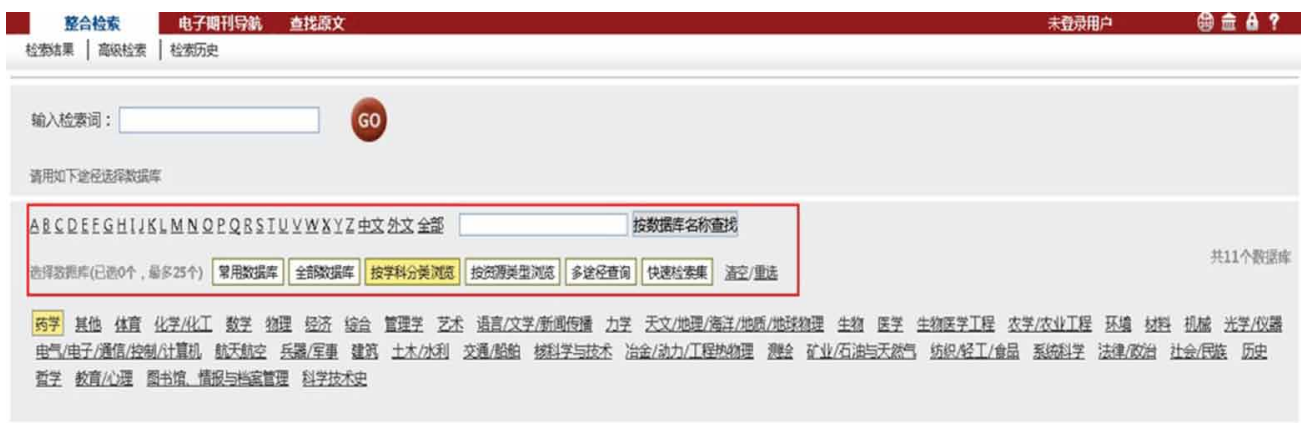

Figure 10.

\begin{tabular}{|c|c|c|c|c|c|}
\hline \multirow[t]{2}{*}{ 求是学术摱索 } & 书刊查询 & 数据库 & 电子图书 & \multicolumn{2}{|c|}{ 电子期刊导航 } \\
\hline & & & & 绍 & 高级格 \\
\hline
\end{tabular}

11. To what extent would you like to receive the resources of other university libraries or resource alliance through your school library system? (Figure 11)
A. A huge extent
B. Quite a huge extent
C. An average extent
D. Quite a limited extent

12. To what extent do you think it is useful to display a brief description of the search term in the search results? (Figure 12)
A. A huge extent
B. Quite a huge extent
C. An average extent
D. Quite a limited extent
E. A limited extent 
Figure 11.

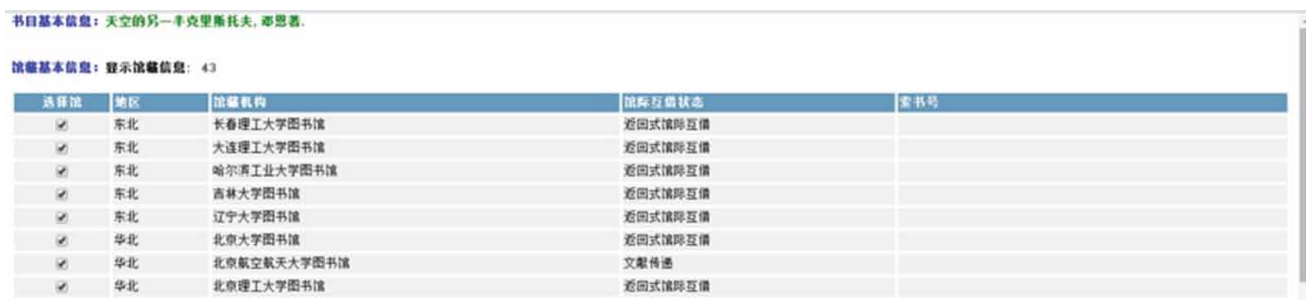

\section{Figure 12.}

车安

李安 (英文: 'Ang Lee'，1954年10月23日)，出生于台湾屏东县，台滦蓄名导演. 目前主要在美国发展. 李安在1999年拍的《卧虎藏

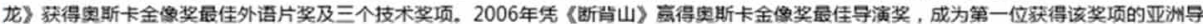
演. 孛安也曾两度获得柏林影展金能奖与威尼斯影展金猩奖的肯定.

13. To what extent do you think it is useful to display a brief description of the search term in the search results? (Figure 13)
A. A huge extent
B. Quite a huge extent
C. An average extent
D. Quite a limited extent
E. A limited extent

Figure 13.

关鍵字 图书情报
找不到任何图书情报导刊
现代图书情报技术 = New Technology of Library and Information Service
图书情报工作 = Library and Information Service
农业图书情报学刊 = Journal of Library and Information Sciences in Agriculture
中华医学图书情报杂志 = Chinese Journal of Medical Library and Information Science
大学图书情报学刊 = Journal of Academic Library and Information Science
图书情报知识 = Document,Information \& Knowledge
中小学图书情报世界
上海高校图书情报工作研究 = Research on Library \& Information Work of Shanghai Colleges \& Universities
浙江高校图书情报工作=Library \& Information Service of Zhejiang Universities \& Colleges

14. Figure 14 shows the common terms automatically prompted by the system when tap into the search box(according to word frequency statistics), Figure 15 shows the standard terms obtained by searching the word list before searching. Which one do you prefer? 

A. Figure 14
B. Figure 15
C. Not to matter

Figure 14.

\begin{tabular}{|c|c|}
\hline information & \\
\hline information & 55 次检寻 \\
\hline information theory & 42 次检呞 \\
\hline information management & 32 次检畓 \\
\hline information retrieval & 32 次检灵 \\
\hline information science & 13 次检疄 \\
\hline information technology project management & 12 次检承 \\
\hline information resources management & 10 次检急 \\
\hline information architecture & 9 次检居 \\
\hline
\end{tabular}

Figure 15.

$\stackrel{\text { Information }}{\square \text { include Synonyms } \square \text { include Dead terms }}$

\begin{tabular}{|c|c|c|}
\hline Career Information Systems & Information Science & Information Transfer \\
\hline community information services & Information science Education & Information Utilization \\
\hline Information centers & Intormation security & Merchandise Information \\
\hline information Dissemination & information seeking & Navigation (Information Systems) \\
\hline Information Literacy & Information services & Dccupational information \\
\hline Information Networks & information Storage & User Needs (Information) \\
\hline Information Policy & Information Systems & User Satistaction (Information) \\
\hline Information Processing & Information Technology & Users (Information) \\
\hline
\end{tabular}

15. To what extent do you think it is automatic error correction function of resource discovery system matters? (Figure 16)
A. A huge extent
B. Quite a huge extent
C. An average extent
D. Quite a limited extent
E. A limited extent

16. To what extent would you like the library resource discovery system to do a pre-retrieval setup in order to narrowing down the scope of your retrieval subject? (Figure 17)
A. A huge extent
B. Quite a huge extent
C. An average extent
D. Quite a limited extent
E. A limited extent 


\section{Figure 16.}

\section{冒李求斯}

网页 新闻贴吧知道 音乐图片 视频 地图 文库 更多》
百度为您找到相关结果约16个

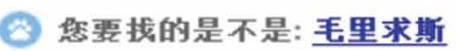

\section{Figure 17.}

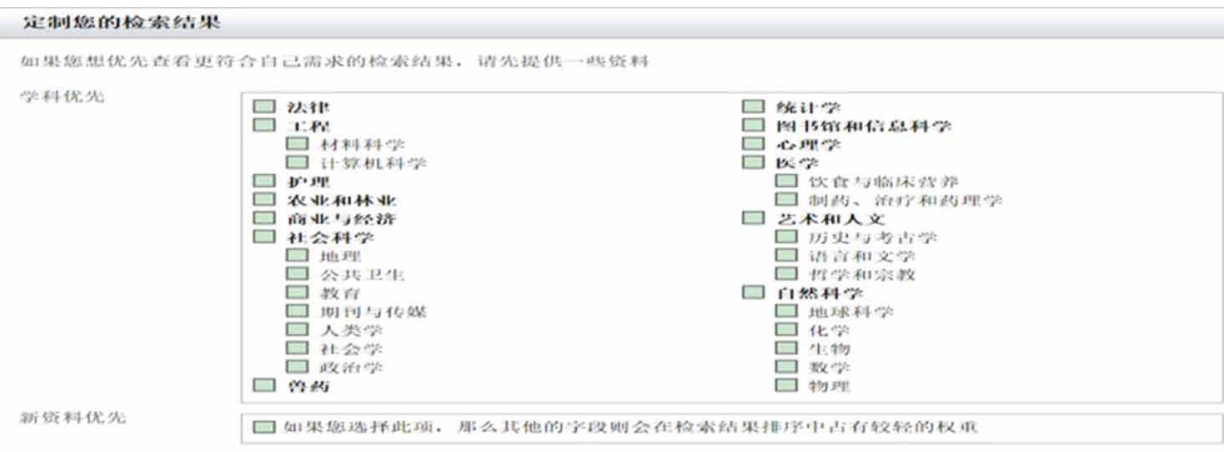

17. When you search "Dream of the Red chamber", which of the following resources do you wish to see? (multiple choice)
A. The original book
B. The adapted edition
C. Journal articles on redology
D. MOOC video related to redology
E. TV series and movies
F. TV theme song and episode
G. Book illustrations or film stills
H. Personal information of the author or famous actors
I. Others

18. What would you like to see displayed in each search result on the library website? (multiple choice)
A. Literature types (such as books, journals, conference papers, multimedia resources, etc.)
B. Title
C. Author
D. Source (book publishing information, paper source journals, etc.)
E. keyword
F. Abstract
G. ISBN
H. Collection location/call number
I. Review 
J. Probation

K. Literature carrier (e.g. paper, electronic or CD-ROM)

L. Version

M. Series

19. To what extent do you think it is important for the retrieval system to provide a detailed description of the authors of the literature? (Figure 18)
A. A huge extent
B. Quite a huge extent
C. An average extent
D. Quite a limited extent
E. A limited extent

Figure 18.

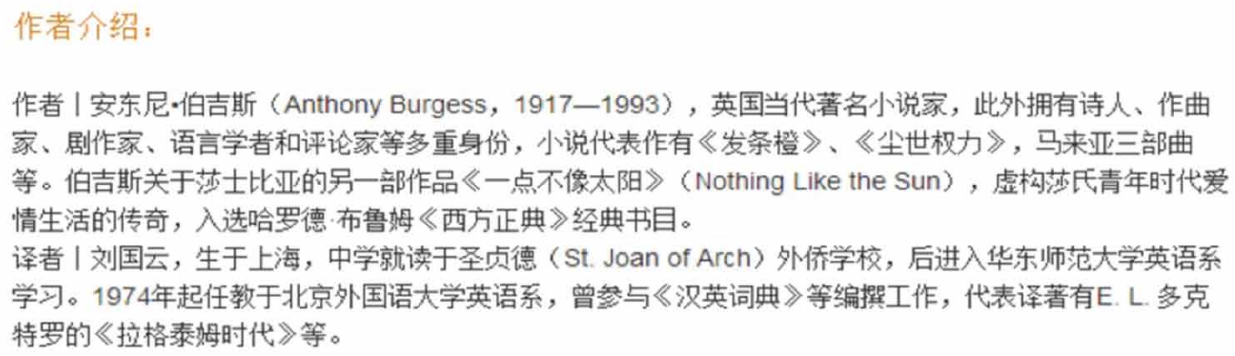

20. To what extent would you like to receive contents of the book catalogue during retrieval? (Figure 19)
A. A huge extent
B. Quite a huge extent
C. An average extent
D. Quite a limited extent
E. A limited extent

21. What information do you want the resource system to provide you when you want to know about a scholar? (Tick off)
A. The research field
B. The institutions
C. The project chaired by the scholar
D. Publications
E. Co-writers
F. The genre

22. Which of the following presentation methods do you think is more suitable for your search?
A. Detailed like Figure 20
B. Simplified like Figure 21
C. Not to matter

23. Do you want the library website to display all kinds of documents in the search results (shown as Figure 22, which contains academic papers, e-books, news, etc.) or to display various types of documents (shown as Figure 23, which contains journals, books, etc.)?
A. Centralized display as Figure 22
B. Classified display as Figure 23 
Figure 19.

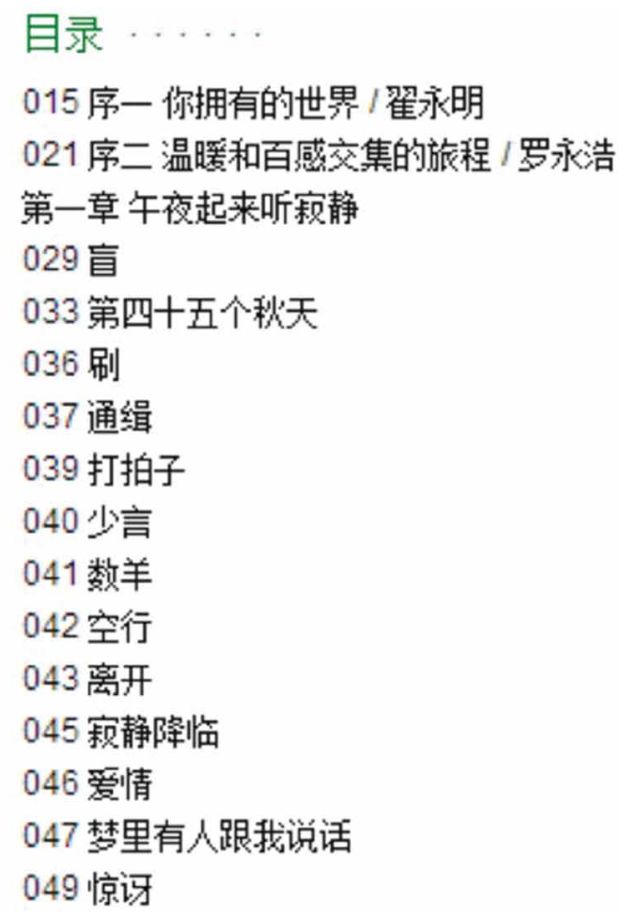

Figure 20.
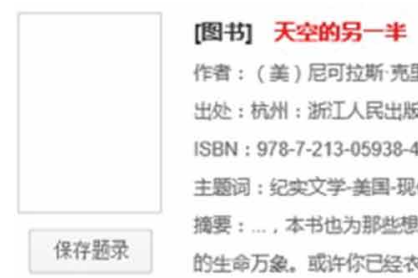

Figure 21.

天空的另一半 $=$ Half the sky

克里斯托夫, N. (Kristof, Nicholas); 邓恩, S. (Wudunn, Sheryl) 吴茵菌 2014

国际标准书号 978-7-213-05938-4 
Figure 22.

44. Consideraţii privind selectarea și ierarhizarea soluțiilor de securitate informaţională.

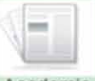

Academic Journal

Considerations on the selection and prioritization of information security solutions. By: RĀDULESCU. Maria Cristina. Audit Financiar. 2016, Vol. 14 Issue 137, p505-574, 22p. Language: Romanian. DOI: 10.20869/AUDITF/2016/137/564. , Database: Business Source Complete

Subjects: Information storage \& retrieval systems -- Security measures: Capital budget; Security management: Economics; Information resources -- Security measures

PDF Full Text (3.3MB)

45. Legal Issues in Information Security

By: Grama, Joanna Lyn. Series: Jones \& Bartlett Learning Information Systems Security \& Assurance Series. Edition: 2nd ed. Burlington, MA : Jones \& Bartlett Learning. 2015. eBook., Database; eBook Index

Subjects: COMPUTERS / Security / Networking: Information storage and retrieval systems-Security measures--Law and legislation--United States; Information storage and retrieval systems-Law and legislation--United States: Data protection--Law and legislation--United States

46. 424B2: UBS AG

In: EDGAR Online-Prospectus and Proxies. May 22, 2013; COMTEX News Network, Inc. Language: English, Database: General OneFile

Subjects: United States; Switzerland; Securities industry; Banking industry: UBS Securities L.L.C.; UBS AG; United States. Securities and Exchange Commission: United States. Internal Revenue Service

Figure 23.

学术期刊 (938)

Study of Web Service Formal Representation and Coordination Level ... Güieojum, Liu... Special Issue on Information Security Chin-Chen Chang, Chis-Chen Lin 《电子科技学刊(英文版… Guest Editorial Special Issue on Information Security Chin-Chen Chans, Chia-Chen Lin 《N... International Code of Conduct for Information Security信息安全国际… 《北家周搌《英..

期刊导航 (63)

«EURASIP Journal on Information Security»

"Iet Information Security"

"Information and Computer Security"

"Information systems security"

学术趋势 (西多)

[雷项]

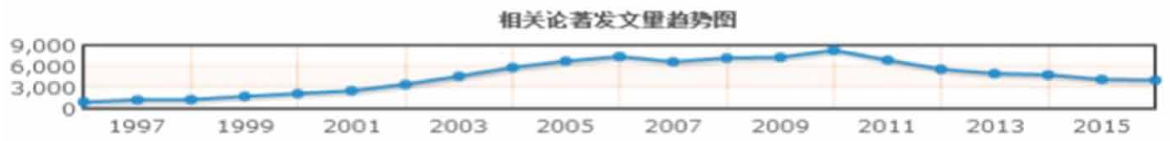

湜 图书章节(5279)

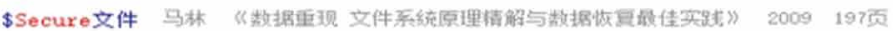

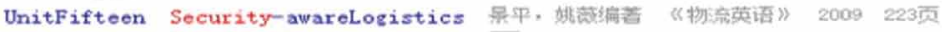

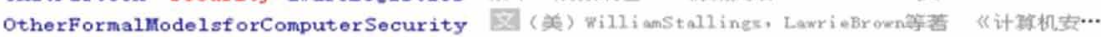

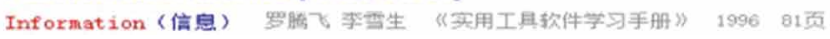

24. How important do you think the following resources are in the resource discovery system? (Grade all kinds of resources with 1 being the most important and 8 being the least)
A. The entity collection
B. Electronic books
C. Journal articles
D. The film and television resources 

E. The blog
F. Academic press
G. Online Q\&A
H. Douban and other comments

25. How would you like the search results on the library website to be arranged?
A. By the correlation degree (the degree of matching between the retrieval form and the retrieval results)
B. By academic (core journals, expert literature and other high-quality literature are ranked in the first place)
C. By reference
D. Ascending and descending order by publication date
E. Priority in terms of collection (priority should be given to the library collections in the search results)
F. By popularity (sorted by number of clicks)
G. Others

26. For electronic resources, what kind of literature reading methods do you expect to be provided by the library website?
A. Online reading (Daokebaba, Google books, etc.)
B. Download and read
C. Mobile terminal reading (by scanning the QR code, etc.)
D. Database purchased by the school (Duxiu, CNKI, Weipu, Wanfang)
E. Amazon electronic resource lending service

27. For the physical resources of the library (such as books, audio and video tapes, etc.), what kind of access do you want to be provided by the library website?
A. The collection location of the resource
B. Library document delivery or interlibrary loan (a resource-sharing model among cooperating libraries in which users can access the resources of other libraries in one library)
C. Mutual transfer among users

28. What analysis functions do you expect from the resource discovery platform? (Figure 24)
A. Publication time
B. Author distribution
C. Publications
D. Literature type
E. Regional distribution
F. Subject distribution
G. Distribution of core journals
H. Others

29. To what extent do you need the function of knowledge map? (The knowledge map can be used to visualize the core structure, development history, frontier fields and overall knowledge structure of the discipline to achieve the purpose of multi-disciplinary integration, and provide practical and valuable reference for discipline research.) (Figure 25)
A. A huge extent
B. Quite a huge extent
C. An average extent
D. Quite a limited extent
E. A limited extent

30. To what extent do you need the function of analyzing the citation relationship of retrieval results? (Figure 26)
A. A huge extent
B. Quite a huge extent 
International Journal of Library and Information Services

Volume $9 \cdot$ Issue $2 \cdot$ July-December 2020

Figure 24.
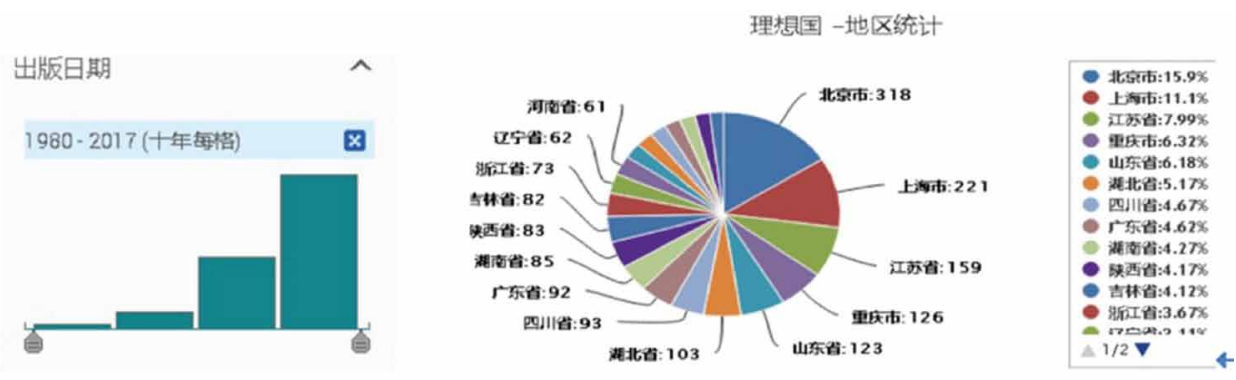

Figure 25.
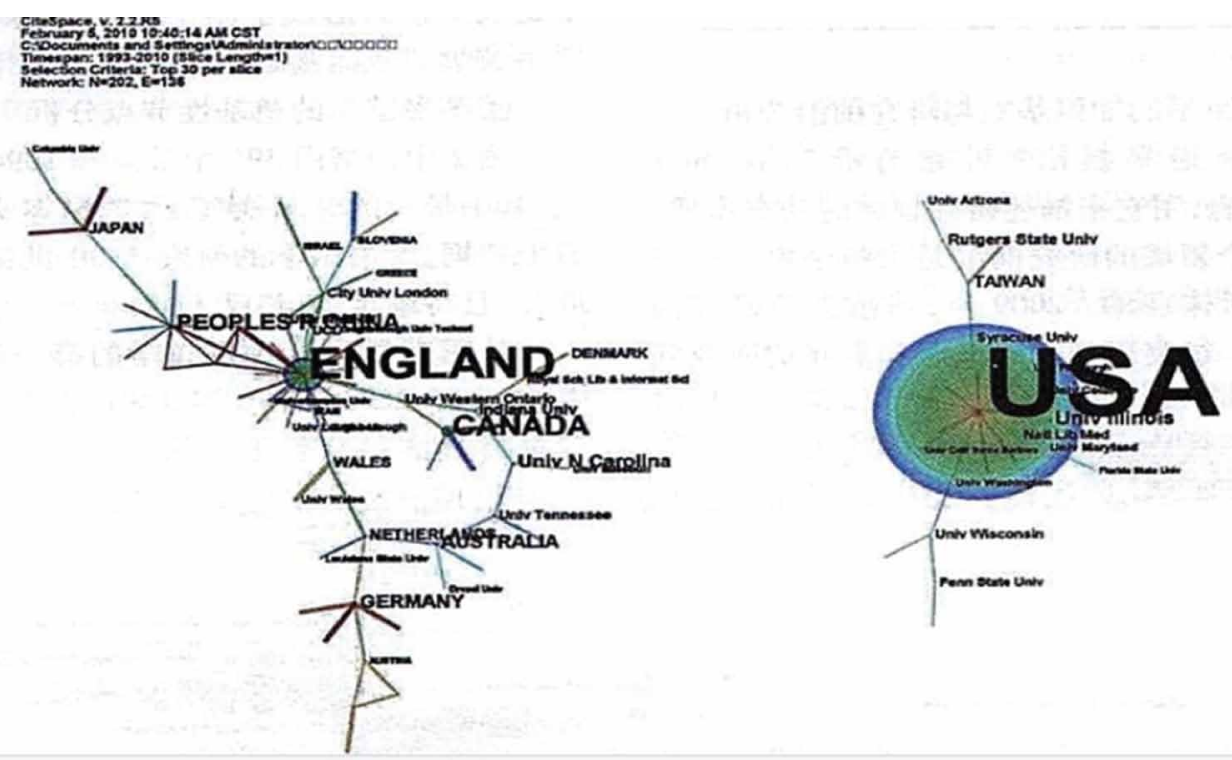

Figure 26.

gy - A proposal for reporting

1. I (Olkin, 1); Williamson, GD Milliamson, GD); Rennie, D (Rennie, D): zker, SE)

Slinical practice and the explosion of information in the scientific

$f$ to address this problem, and they often evaluate observational studies. nalyses of observational studies and to make recommendations to aid

on expertise in clinical practice, trials, statistics, epidemiology, social terested scientists. Funding for this activity was provided by the Centers

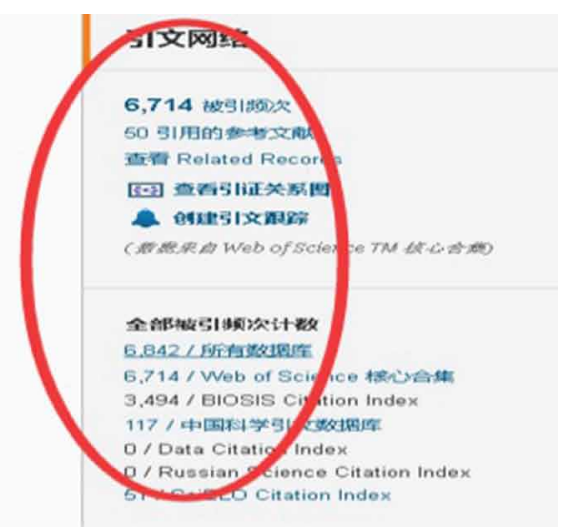



C. An average extent
D. Quite a limited extent
E. A limited extent

31. What kind of visualization do you want the library resource discovery system to provide? (optional) A Figure 27 Connection of author nodes

B. Figure 28 Connection of knowledge nodes

C. Figure 29 Citation analysis

\section{Figure 27. Connection of author nodes}

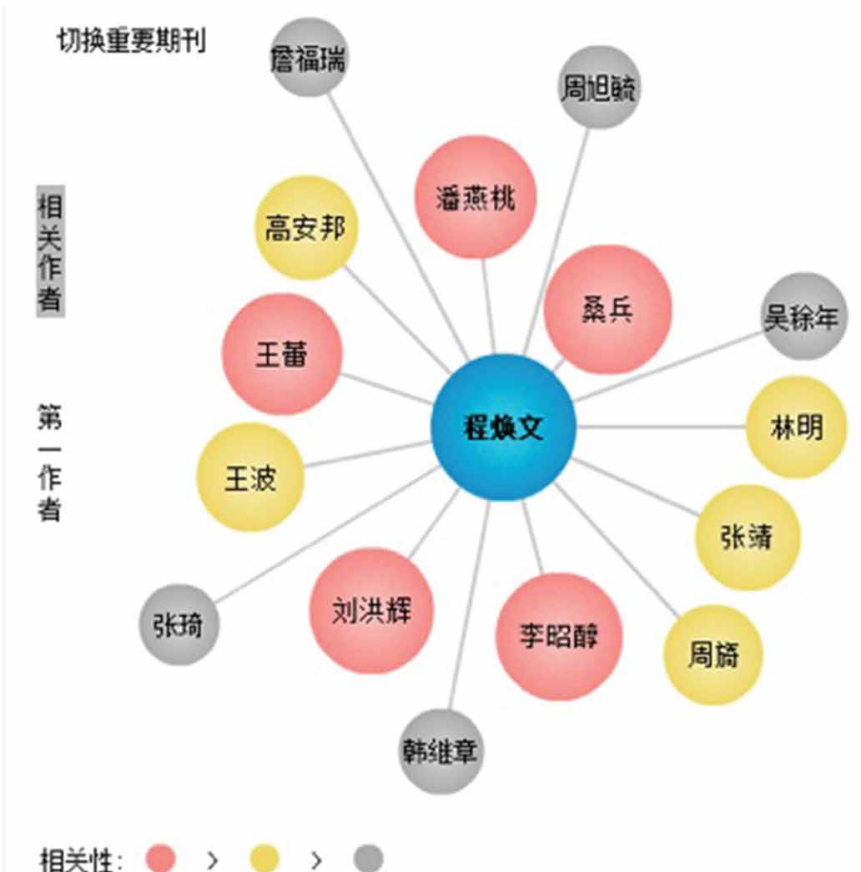

32. To what extent would you like the retrieval system to record your retrieval preferences and provide a resource push service?
A. A huge extent
B. Quite a huge extent
C. An average extent
D. Quite a limited extent
E. A limited extent

33. To what extent would you like the search system to push research hotspots in different research fields automatically? (Figure 30)
A. A huge extent
B. Quite a huge extent
C. An average extent
D. Quite a limited extent
E. A limited extent 
Figure 28. Connection of knowledge nodes

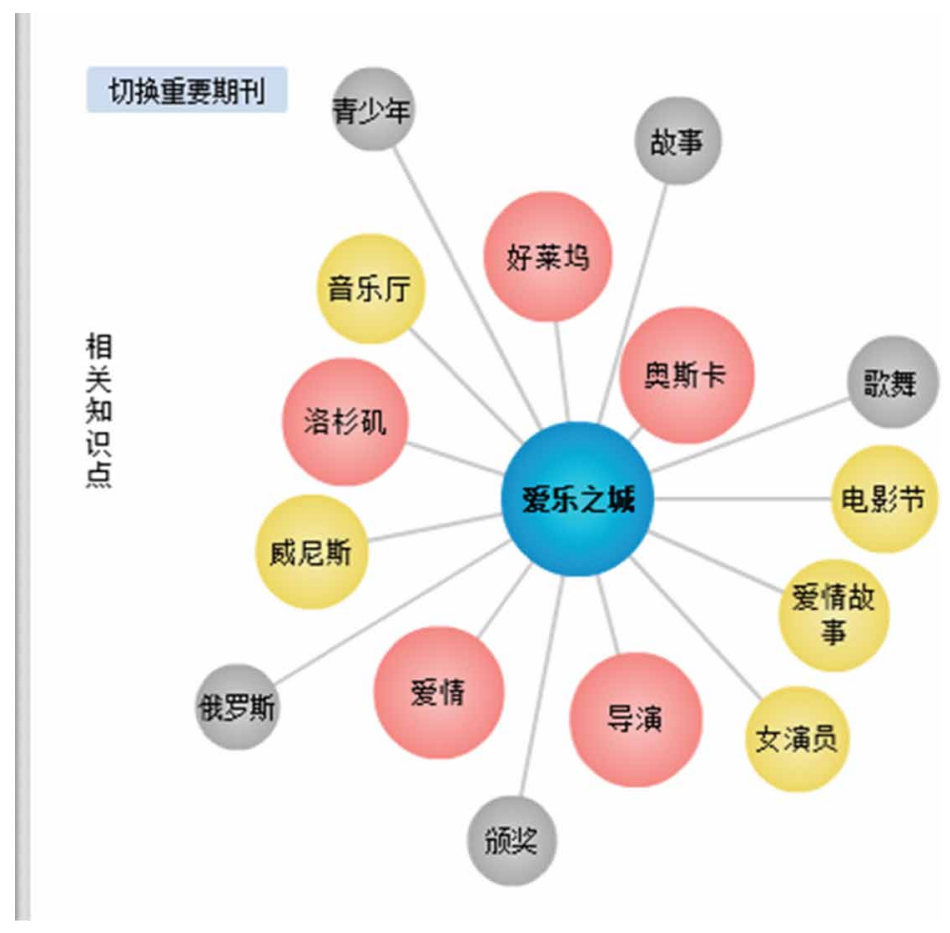

Figure 29. Citation analysis

参考文献与引证文献:

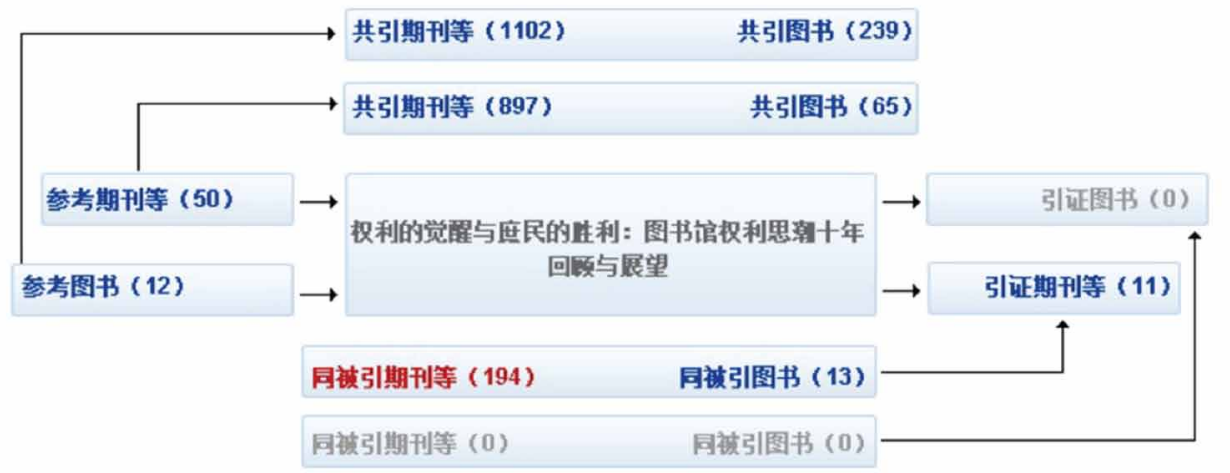

34. To what extent would you like the retrieval system to push highly cited articles from different research fields? (Figure 31)
A. A huge extent
B. Quite a huge extent
C. An average extent
D. Quite a limited extent
E. A limited extent 
Figure 30.

\section{研究热点}

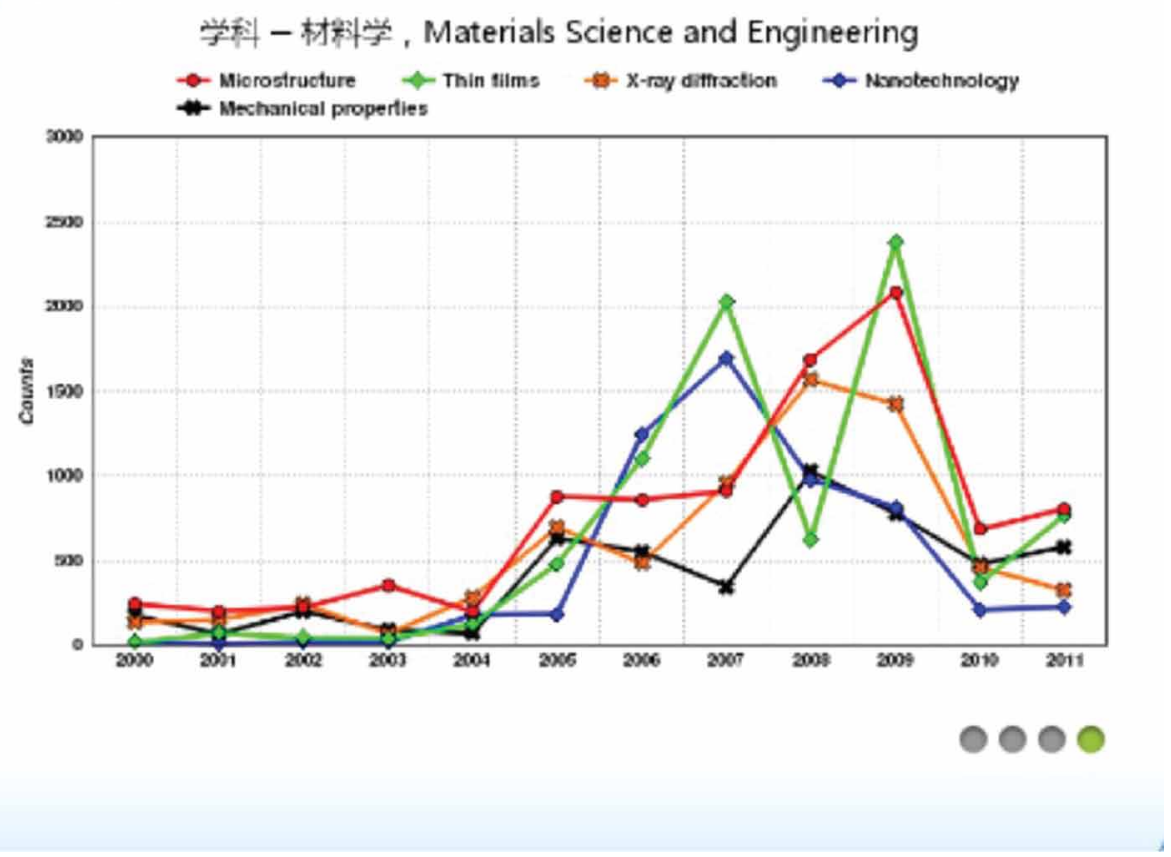

Figure 31 .

\begin{tabular}{|c|c|}
\hline 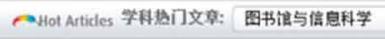 & 482017 ? \\
\hline \multicolumn{2}{|c|}{$\begin{array}{l}\text { Bloorm's taxonomy of cognitive learning objectives } \\
\text { Adams. Nancy E, Journal of the Meacalin Lbrary Association (2015) }\end{array}$} \\
\hline \multicolumn{2}{|c|}{$\begin{array}{l}\text { Strategies for ensuring trustworthiness in qualitative research projects. } \\
\text { Shenton, Andrew } K \text { KEvucatoon for information (2004) }\end{array}$} \\
\hline \multicolumn{2}{|l|}{$\begin{array}{l}\text { How to Write an Annotated Bibliography } \\
\text { Kang, Jenniter, Accoss (2010) }\end{array}$} \\
\hline 更多... & $\overline{\text { cooste }}$ Ex ExLíbris bx \\
\hline
\end{tabular}

35. To what extent would you like the library website to push relevant meetings, lectures and other contents about the topic you are interested in? (Figure 32)
A. A huge extent
B. Quite a huge extent
C. An average extent
D. Quite a limited extent
E. A limited extent

36. When you have a search record in the library resource discovery system, what resources do you expect to be pushed to the platform besides relevant books and periodicals?
A. A certain kind of professional resources
B. Contribution agencies
C. Recommended movies and e-books
D. Bookstore
E. Study or discuss community 
Figure 32.

Name:

Your RSS feed:

Searched for:

Databases:

Includes:

Expiration:

Date created:

Date modified:

\section{Modify RSS feed}

ProQuest: information sharing

http://feeds. proquest.com/rss/528231

information sharing

18 databases searched View list

Newly published results only

Feed expires if not accessed for $\mathbf{3}$ Months

May 062017

May 062017

강 View results $\mathbf{x}$ Delete

F. Relevant bloggers or respondents

G.PDF, PPT, audio, etc.

H. Others

37. How do you want to get personalized information push?
A. Access the library
B. Email push
C. Message push
D. Social software alerts (e.g. WeChat, QQ)
E. RSS subscription

38. Which of the following subjects would you like to communicate with through the academic interactive Q\&A platform? (optional)
A. Experts in relevant disciplines
B. Students in relevant scientific research fields
C. All registered users of the system
D. Others

39. To what extent would you like the library to set up the user review function?
A. A huge extent
B. Quite a huge extent
C. An average extent
D. Quite a limited extent
E. A limited extent

40. In the process of literature retrieval, will you add labels to the literature by yourself?
A. Very often
B. Often
C. Generally
D. Occasionally
E. Never

41. Do you usually use mobile APP to search academic resources?
A. Very often
B. Often
C. Generally
D. Occasionally
E. Never 
42. To what extent would you like the library website to provide the function of collecting resources, so that you can collect the content you are interested in and put it in the specific collection folder, which is convenient for you to browse and use? (Figure 33)
A. A huge extent
B. Quite a huge extent
C. An average extent
D. Quite a limited extent
E. A limited extent

43. What reference services would you like the library website to provide?
A. Search assistance
B. System using assistance
C. Technology innovation assistance
D. Thesis detection
E. Literature delivery
F. Special consultation (for a specific problem, search information for users and provide retrieval report)
G. Database using guide

44. What other services would you like the library website to provide?
A. Thesis detection
B. Audiobooks
C. Mobile APP
D. Virtual learning space (a virtual space where users can access online learning resources and communicate with other users)

45. What audiobooks would you like the library website to provide?
A. Literary novels
B. English listening
C. News
D. Conference and lecture
E. Folk art programs
F. Celebrity interviews

46. When the full text cannot be found in the resource discovery system, how do you solve it?
A. By literature delivery
B. By searching online resources
C. Others

47. Have you ever used the function of document mutual assistance? What do you usually do when you failed to find the full text of the literature?

48. Do you have met any dissatisfaction during using the library resource discovery system? (Open question) 
Figure 33.

\begin{tabular}{|c|c|c|c|c|}
\hline 收藏到书房 & $x$ & 㹃： & 默认排序 & I \\
\hline & 新建文件夹 & & & \\
\hline 根目录 & & & 收践 & + 分享到 \\
\hline 舟棺 论文 & 打开 & & & \\
\hline 宋节 图书 & 打开 & & & \\
\hline
\end{tabular}

Linlin Song is an associate professor at School of Information Management in Sun Yat-sen University since 2011. She received her Ph.D. degree in the field of Library Science from Wuhan University in 2011. She was a visiting scholar at School of information science, University of Illinois, Champaign-Urbana, in 2017. She has published in Journal of Education for Library and Information Science, Archival Science, and in Chinese research journals, Such as Journal of Library Science in China, Library and Information Service. Her research interests are information organization and retrieval.

Haitao $\mathrm{Li}$ is the corresponding author of the paper.and he is an associate professor at School of Information Management in Sun Yat-sen University since 2011. He received his Ph.D. degree in the field of Archival Science from Wuhan University in 2011. He was a visiting scholar at School of Information Studies, University of WisconsinMilwaukee, in 2016. He has published in Archival Science, and in Chinese research journals, Such as Archives Science Study, Journal of The China Society for Scientific and Technical Information and Journal of Library Science in China. His research interests are archival management, information organization and information user behavior.

Shihui Li is a junior student in archival science major, at School of Information Management in Sun Yat-sen University from 2015 to nowadays. As the member of research group in charged by Doctor Haitao Li, she shows her good abilities in archival management and information organization. 